\title{
Structuring the Jungle of Capabilities Fostering Digital Innovation
}

\author{
Christoph Buck ${ }^{1,2}$, Timo Grüneke ${ }^{3,4}$, and Katharina Stelzl ${ }^{3,4}$ \\ ${ }^{1}$ Centre for Future Enterprise, QUT Business School, Queensland University of Technology, \\ Brisbane, Australia \\ \{christoph.buck\}@qut.edu.au \\ ${ }^{2}$ Philipps-Universität Marburg, Marburg, Germany \\ \{christoph.buck\}@wiwi.uni-marburg. de \\ ${ }^{3}$ FIM Research Center, University of Bayreuth, Bayreuth, Germany \\ \{timo.grueneke, katharina.stelzl\}@fim-rc.de \\ ${ }^{4}$ Project Group Business and Information Systems Engineering of Fraunhofer FIT, Bayreuth, \\ Germany \\ \{timo.grueneke, katharina.stelzl\}@fit.fraunhofer.de
}

\begin{abstract}
Driven by digitalization, the business environment is changing at an increasing pace. To be able to react to this, organizations must gain competitive advantages through Digital Innovation (DI). This special form of innovation requires a reorganization and further development of the resource and capability base of an organization. The existing literature shows a proliferation of definitions and a jungle of individual capabilities with regard to DI. Based on a structured literature review and a qualitative analysis of existing capabilities, the paper presents a DI Capability Model. By structuring layers, areas and associated capabilities, the model provides the first holistic view in the literature. It will serve as a basis for a targeted scientific discourse and a valuable orientation model for the development of a capability composition to foster DI in organizations.
\end{abstract}

Keywords: Capability Model, Digital Innovation, Digital Innovation Capability, Systematic Literature Review, Dynamic Capability

\section{Motivation}

Advancements in digital technology are transforming businesses and society at a furious pace as they become an inherent part of our daily routines and fundamentally change the way people work, communicate, and consume [1]. These changes create both, completely new markets and satisfy changed customer needs what makes them inherently disruptive. Therefore, incumbent organizations are facing rapid market dynamics and constant change within an intensive and competitive environment [2].

To withstand these rapid developments in a digital world and continue to establish competitive advantages, organizations must increasingly reinvent themselves and drive digital innovation (DI) [1, 3]. Early studies on DI focused on the digitalization of internal processes [1, 4], while upcoming Information Systems (IS) research investigates 
digital technologies and their transformative effect on products, services, and business models [5-7], e.g., by adding digital capabilities to physical products [7]. However, the convergence of several domains, new processes, methods, and conditions as well as speeds of innovation in the digital era, require various developments of resources, processes, and capabilities for DI [8-10].

Although there is a consensus in the literature that DI requires new capabilities and, if necessary, a reorganization of existing capabilities [11], the scientific discourse lacks a holistic view. Different disciplines view innovation induced by digital technologies from very limited perspectives. IS research, for example, distinguishes between information technology (IT) assets and IT capabilities and refers to the latter as capabilities with a potential creation of competitive advantage $[12,13]$, as they are firm-specific and difficult to imitate [14]. Various authors emphasize that digital capabilities are the skills and routines needed to leverage digital assets to create value $[13,15,16]$. This brings in a digital flavor to the broader perspective of management research which postulates the concept of dynamic capabilities [17-20].

Despite a broad body of literature on dynamic capabilities and innovation capabilities, the scientific discourse has not yet been able to identify and link the necessary capabilities for DI by mapping them holistically. Due to the high relevance of DI and a jungle of perspectives and partial considerations of capabilities being relevant to foster DI, we pose the following research question: What capabilities do organizations need to foster digital innovation?

To answer this research question, we conducted a structured literature review (SLR) to identify relevant capabilities. Based on a qualitative analysis, we were able to condense the identified capabilities and developed a DI Capability Model representing a comprehensive, qualified, and structured state of the current scientific discourse. The DI Capability Model comprises nine capability layers, 26 capability areas, and 58 capabilities that are discussed in 74 high-quality scientific articles.

The paper is structured as following. In the next chapter, we show the relationship between DI and organizational capabilities. In chapter 3, we describe the structured literature review and the applied analysis. Chapter 4 presents the DI Capability Model. The article concludes with a conclusion, discussion, and ideas for further research.

\section{Theoretical Background}

\subsection{Digital Innovation}

In dynamic business environments characterized by technological advancements, blurred markets, short product life cycles, and changing customer needs, DI is crucial for organisations to sense, seize, and transform upcoming opportunities (and threats) to maintain competitive advantage $[1,12,21]$. Hence, $D I$ is defined as the 'use of digital technology during the process of innovating' [22] as a means or an end [6]. Digital technologies extract, create, analyse, communicate, or use information in specific contexts [23]. Thereby, we refer to the term 'innovative' as something that is perceived as 
new by the respective organization, where "it matters little $[\ldots]$ whether or not an idea is objectively new as measured by the lapse of time" [24].

To transfer upcoming opportunities into DI initiatives, the DI process comprises four phases: the initiation, development, implementation, and exploitation phase [3]. Moreover, recent research underpins the importance of capabilities to foster DI [1, 3]. However, a holistic view on what capabilities are required is missing. To better understand capabilities and related concepts in general, we provide insights on the role of capabilities to gain competitive advantage in chapter 2.2 .

\subsection{Organizational Capabilities}

According to the resource-based view (RBV), organizations achieve competitive advantage by the composition of its resources for the generation of value [25]. Following [26], this is "the match an organization makes between its internal resources and skills and the opportunities and risks created by its external environment." Taking account for dynamic environments and the emergence of digital technologies, the dynamic capabilities view (DCV) has extended the RBV [18]. Accordingly, resources are divided into assets and capabilities [27]. Assets can be either tangible or intangible and are (in-) permanently at the power of disposition by the organization [20]. Intangible assets further split into intellectual and cultural assets [28]. Capabilities are tacit resources located in people and developed through learning [29]. Hence, capabilities are about the ease of performing an action that is required in a given situation [30].

More precise, organizational capabilities are "the capacity of an organization to purposefully create, extend, or modify its resource base" [31]. Hence, they are "socially complex routines that determine the efficiency with which organizations physically transform inputs into outputs" [32]. According to the DCV, an organization possesses both ordinary and dynamic capabilities [33]. Ordinary capabilities relate to "the performance of administrative, operational, and governance-related functions that are (technically) necessary to accomplish tasks" [34]. Dynamic capabilities emerge from organizational learning [35] and change over time [17].

A similar, but more detailed classification of capabilities differentiates between capabilities that contribute to gaining competitive advantages and therefore introduce the modes 'off' and 'on' or, in a figurative sense, the states 0 and 1. According to [33], the notation of 'zero-order' describes "how we earn a living now capabilities". These capabilities are the ability to perform the essential operational activities of the organization in the day-to-day business $[32,33]$ and, thus, do not necessarily further the course of its overall performance. By contrast, 'first-order' capabilities are dynamic in their nature and contribute somewhat to the performance of the organization and enable competitive advantages to be obtained. They are allocated to a continuum, starting from a lower to a higher level. First-order lower capabilities constitute change and directly influence an organizations' outcome by using existing capabilities to their advantage. First-order higher capabilities create new capabilities through learning. These capabilities thus not only take advantage of all three dynamic components (sensing, seizing, and transforming) but act on this basis herein creating a competitive advantage. 


\section{$3 \quad$ Research Method}

To answer the research question, we used the methodology of a SLR to derive a type two theory for the IS discipline [36]. A SLR allows us to structure and to assess the current state of research in the field of capabilities. Furthermore, reviewing the literature is crucial to advancing any scientific discipline [37, 38]. In our case, we were able to identify reviews trying to unite and illuminate different literature directions on capabilities. To the best of our knowledge, no review has yet been able to compile a multitude of definitions and relate them to DI. To close this gap, we follow [37] complemented by techniques of [39] to conduct our SLR. Subsequently, we derived four search strings (("organization* capabilit*" OR "organisation* capabilit*”); (dynamic capabilit*) AND (innovation capabilit*); ("digital* capabilit*"); ("information technology capabilit*" OR "information systems capabilit" OR "IT capabilit*" OR "IS capabilit*")) from our research questions to be found within the topic (title, abstract, author keywords, and Keywords Plus) of the search engine Web of Science. By applying our search strings, we initially found $(n=6017)$ articles from Web of Science. We checked for duplets $(\mathrm{n}=18)$ as we conducted every search separately resulting in $(\mathrm{n}=5999)$. As stated above, research on capabilities is located at the intersection of several research streams, prompting us to identify high-quality research (relevance and citation performance) from journal publications. Thereupon we used the SCImago journal rank (SJR) indicator [32] as quality criteria and excluded journals and consequently articles with an SJR of less than 4.0 or none. For the remaining articles $(n=375)$ we adopted inclusion criteria to further narrow down our set. This was achieved by screening titles and abstracts and evaluating articles for their RQ relevance from 'low' (score = 1; no connection to the research question) to 'high' (score $=4$; article deals with a capability and clear connection to the research question). Only articles scoring three or four were included into our final set $(n=115)$ and after full-text screening $(n=74)$ were included into our DI Capability Model.

For the analysis of the research contributions, we extended the method of a SLR by adding grounded theory techniques [39]. Thereby, we based our approach on the three coding steps of open coding, axial coding, and selective coding. As a first step, we identified relevant definitions of capabilities in each article. One author initially coded interesting sections and a second author then confirmed the coding in MAXQDA. Subsequently, from about 500 initial codes in 115 articles axial coding focused on identifying capability areas (CA) and overarching capability layers as well as the relationships between the originally coded capabilities. Furthermore, insufficient definitions and code refinement resulted in about 300 codings and 74 articles used. Finally, several iterative cycles of selective coding were performed to refine the CA and layers. The rearranging, merging of layers (e.g., learning-related and knowledge-related capability layer) and the assignment as zero- or first-order capabilities resulted in nine capability layers, 26 capability areas, and 58 capabilities. 


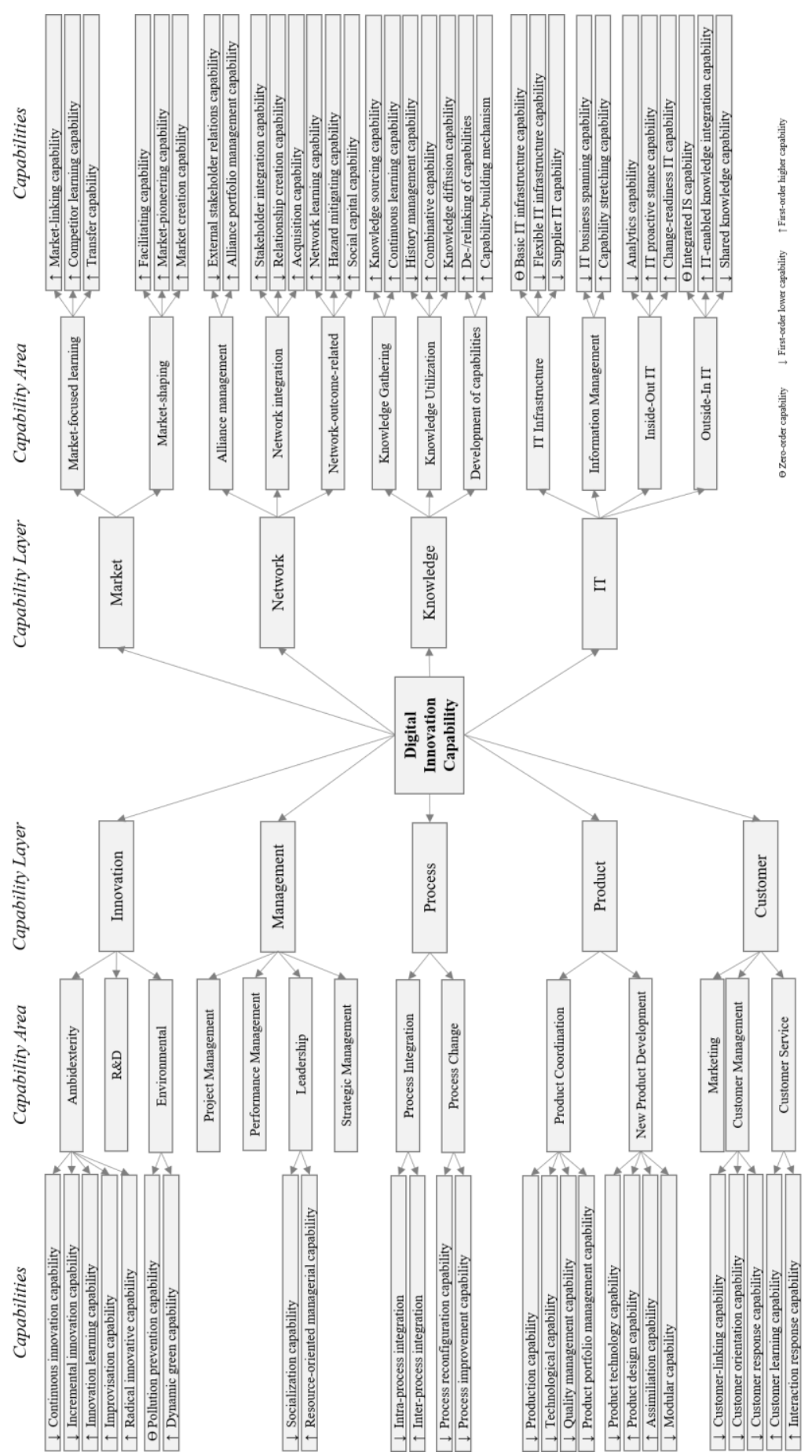

Figure 1. Digital Innovation Capability Model 


\section{Digital Innovation Capability Model}

Structuring the jungle of capabilities required for DI, the DI Capability Model identifies and links capabilities nurturing DI. Therefore, it comprises layers including underlying $\mathrm{CA}$ and capabilities. It is important to note that all layers, CA, and capabilities are interrelated even though they are presented separated. Moreover, each capability is classified as a zero-order $(\Theta)$, first-order lower $(\downarrow)$, or first-order higher $(\uparrow)$ capability. Figure 1 shows the DI Capability Model, detailed descriptions are provided below.

Innovation-related capability layer: This layer comprises capabilities that foster innovation by adding value through offering a new product or service that, in turn, increases competitiveness. The CA of Ambidexterity emphasizes the ability to enhance or generate and nurture new ideas that lead to new product offerings through known patterns of action [40]. This can be achieved by structured evaluation of and exploiting the existing ( $\downarrow$ Continuous innovation capability $[41,42]$ ) as well as in enhancing products or services ( $\downarrow$ Incremental innovation capability [43]). By contrast, this CA also aims for exploring the new ( $\uparrow$ Innovation learning capability) and includes spontaneous actions to react to an unknown situation with novel solutions by drawing from existing knowledge ( $\uparrow$ Improvisation capability). If the exploration is conducted, transformational outcomes may occur changing products and enhancing organizational capabilities ( $\uparrow$ Radical innovative capability $[10,43])$. Research and Development is a CA which resembles the ability to build new technologies by assembling new technical resources and evaluating them. This can be achieved through the research ability to identify, understand, assess, and apply internal and external knowledge [19, 44-48]. Capabilities subject to the Environmental CA contribute towards aligning organization's operations in an environmentally friendly manner. On the one hand, it focuses on reducing pollution ( $\Theta$ Pollution prevention capability), on the other it aims to closely interact with stakeholders and reconfigure organizationally embedded resources to build complementary green capacities ( $\uparrow$ Dynamic green capability).

Management-related capability layer: This layer focuses on capabilities being relevant for managing an organization. The Project Management CA describes the ability to understand the requirements a client desires as well as the design of products. Moreover, it focuses on the budgeting of total time requirements and the efficient use of resources [49]. The Performance Management CA describes the ability to establish monitoring, evaluation, and control systems to oversee the organizational performance and steer management initiatives [50]. The Strategic Management CA defines the ability to direct resources appropriately to achieve organizational goals. By providing guidance on existing strategies, strategic management can also help to align activities with objectives or to assist in deciding on strategic goals and allocating appropriate resources [51]. The Leadership CA is connected to the ability to establish a shared believe system and organizational culture ( $\downarrow$ Socialization capability $[52,53])$. Part of this is the ability to guide organizations systematically through the process of resource reconfiguration and transformation activities ( $\uparrow$ Resource-oriented managerial capability [54]). 
Process-related capability layer: This layer integrates capabilities related to the management of processes. They are not limited to one respective field but interact throughout organizational levels. The CA of Process Integration defines the ability to create and coordinate digital connections between entities and to coordinate them. Looking inside the organizations, entities resemble to resources or activities and are production oriented ( $\downarrow$ Intrafirm process integration capability [55]). Looking outside, entities lie outside and need coordination of transaction interdependencies ( $\uparrow$ Interfirm process integration capability [55]). The Process Change CA describes the ability to modify processes (e.g., routine processes) through targeted reorganization, improving existing processes, and learning new processes ( $\downarrow$ Process reconfiguration capability [56]). Change also occurs by systematic enhancement of existing processes to streamline activities ( $\downarrow$ Process improvement capability [57]).

Product-related capability layer: This layer deals with capabilities that are related to the process of producing and changing products or activities [50, 58]. Capabilities to obtain a product are clustered in the CA Product Coordination. This CA deals with capabilities that enable organizations to convert multiple inputs into outputs ( $\downarrow$ Production capability [59]). To achieve this, it is necessary to use different technologies ( $\downarrow$ Technological capability [48, 60-62]). Furthermore, the conversion process must be monitored using quality criteria and requires the elimination of errors ( $\downarrow$ Quality management capability). At the same time, a product portfolio must manage the trade-off between short-term demands for performance and long-term development of capabilities ( $\downarrow$ Product Portfolio Management [56]). The New Product Development CA unites capabilities that support the creation of new products, thus changing the product portfolio offered by using technological components ( $\downarrow$ Product technology capability [63]). To create new products, design elements can be rearranged ( $\uparrow$ Product design capability [64]) and inputs for new product development or adaptation can be included ( $\uparrow$ Assimilation capability [65]). Therefore, an interplay between a problem-solving process and resulting performance criteria is required ( $\downarrow$ Modular capability [66]).

Customer-related capability layer: All capabilities that help organizations to address or interact with the customer are gathered in this layer. It is not only dealing with CA that describe capabilities to serve current (e.g., latest needs and expectations) but also to create relationship with new customers. It is closely linked to the market-related capability layer and partly overlaps. The Customer Management CA focuses on fostering established relationships with customers but also to integrate them into innovation activities. This is achieved through the management of relationships ( $\downarrow$ Customer-linking capability [61, 63]), the monitoring of needs ( $\downarrow$ Customer orientation capability [67]), and the response to needs ( $\downarrow$ Customer response capability [49, 67]). The Marketing CA comprising marketing capabilities that are used in a broader sense to describe the two capability-layers customer and market [47, 48, 60-62, 68] but also just customers $[44,69]$ or just market [46]. In terms of Customer Service, this CA focuses on the activity of offering products to the customer [67]. The ability to learn and create knowhow ( $\uparrow$ Customer learning capability [42]) about the needs (e.g., customer orientation capability) allows for the integration into novel products through the interaction with the customer ( $\uparrow$ Interaction response capability [70]). 
Market-related capability layer. This layer comprises capabilities being relevant for markets, i.e., places where entities exchange goods and services subject to the influence of externalities [62]. The Market Focused Learning CA focuses in contrary to customer learning, additionally on other entities present in the market to integrate the respective knowledge [68]. This allows to monitor the market and reflect changes enabling timely measures of action ( $\uparrow$ Market-linking capability [61]). Such entities might be competitors to learn from ( $\uparrow$ Competitor learning capability [42]) in order to replicate product offerings or facilitate abilities to transfer the offerings to different markets ( $\uparrow$ Transfer capability [62, 65, 71]). The Market Shaping CA provides capabilities that make it possible to gather valuable information to discover new linkages of resources ( $\uparrow$ Facilitating capability [64, 72, 73]), propose them to the market, and thereby shaping its nature [72]. The discovery of new links provides organizations with a head start resulting in a higher learning curve and enables the creation of a new market ( $\uparrow$ Market-pioneering capability and $\uparrow$ Market creation capability [74]).

Network-related capability layer: This layer allows organizations to connect with other organizations but also customers [68, 75]. The Alliance Management CA refers to the management of external linkages to exchange operation experience [76]. These linkages occur, e.g., with suppliers as stakeholders wanting information on their past performance ( $\downarrow$ External stakeholder relations capability [51]). Likewise, the supplier might share knowledge or information the organization seeks enabled through the relationship. These exchange processes are not limited to one stakeholder but to a portfolio that needs managing. This allows organizations to tap into different knowledge pools that can be absorbed for own use ( $\uparrow$ Alliance portfolio management capability [77]). The Network Integration CA goes one step further than the management of alliances. It actively integrates stakeholders into organizational activities ( $\uparrow$ Stakeholder integration capability [41, 61]). Managing linkages to external entities can also be focused on leading an innovation network. This network can either be closed aiming at a collective innovation effort or open. In the latter, the organization acts as a facilitator or incubator for other innovators thereby learning from the entity ( $\uparrow$ Network orchestration [78]). Thus, the ability to nurture the external relationship is the basis for integration. The extreme of integration is the actual acquisition of the network partner to absorb its resources to extend and mix them with own ones ( $\uparrow$ Acquisition capability $[62,65])$. The Network Outcome-related CA subsumes capabilities that underpin the results from established linkages with stakeholders. This outlines the organization's learning and sense-making capabilities but also share knowledge e.g., with suppliers ( $\uparrow$ Network learning capability [42, 68, 79]). Besides, capabilities to reduce risk referring to collaborative agreements ( $\downarrow$ Hazard mitigating capability [80]) as well as capabilities to gain advantage of memberships in social networks are important ( $\uparrow$ Social capital capability [64]).

Knowledge-related capability layer: When talking about organizational knowledge and its integration we tap into the research stream of absorptive capacity. This research stream is relevant in IS and DI due to its manifold contributions, constructs, and implications [52, 81]. This layer summarizes knowledge-based (focus on knowledge collection) and learning-related capabilities (focus on learning from knowledge). The 
Knowledge Gathering CA in its core captures the knowledge (e.g., technology trends) relevant to organizations to store in repositories. This knowledge then can be used to inform activities such as innovation ( $\uparrow$ Knowledge sourcing capability [82-85]). Activity outcomes from that utilization thus inform the knowledge repositories continuing the knowledge gathering ( $\uparrow$ Continuous learning capability [41]). The Knowledge Utilization CA compared to gathering makes use of the knowledge. One way is to draw on an organizations' history to control its perceptions and derive insights to guide actions ( $\downarrow$ History management capability $[53,83,86]$ ). Among this CA is the ability of organizations to not only build up knowledge from internal sources, but to integrate and (re-) combine knowledge to gain new insights ( $\uparrow$ Combinative capability $[53,68,82,85]$ ). It is also important to be able to circulate knowledge within the organization ( $\uparrow$ Knowledge diffusion capability [52, 65, 84, 85]). Otherwise knowledge silos occur, so that knowledge is not used. The CA of Development of Capabilities delinks capabilities from areas they have already been applied to and relinks them to new areas ( $\uparrow D e$ /relinking of capabilities [62]). Eventually, the organization has the capacity to build new capabilities, which is not a matter of selecting new resources, but of adding value to existing ( $\uparrow$ Capability-building mechanism $[47,64,73])$.

IT-related capability layer: This layer is defined "[...] as [the] ability to mobilize and deploy IT-based resources in combination or copresent with other resources and capabilities" [12] and is adapted by other authors [87-90]. The IT Infrastructure CA includes capabilities that enable generally usable systems to be provided, e.g., to communicate via suitable application systems ( $\Theta$ Basic IT infrastructure capability [91]). Environmental influences challenge IT to develop and implement quickly and, thus, gain importance to react to internal or external changes ( $\downarrow$ Flexible IT infrastructure capability [92]). Lastly, organizations can also use systems provided by a third party such as suppliers including complementary service offerings ( $\downarrow$ Supplier IT capability [93]). The CA Information Management incorporates capabilities that use IT infrastructure to serve users with data and information [50]. It enables the integration and transformation of knowledge as well as the use of its resources to improve the accomplishment of organizational goals ( $\downarrow$ IT business spanning capability $[52,91])$. It also covers the ability to extend current capabilities to develop a new product requiring capabilities or knowledge not yet acquired ( $\uparrow$ Capability stretching capability [94]). Capabilities in the Inside-out IT CA help to make use of IT infrastructure and Information Management to increase knowledge application within the organization [52]. Insights are generated through the analysis and transformation of data ( $\downarrow$ Analytics capability [95]). Besides, the ability to create new business opportunities through searching for exploitation of IT resources or the embrace of novel IT innovations belongs into this CA ( $\uparrow$ IT proactive stance capability [91, 96]). To do so, the IT needs to be open for change to enable the delivery of competitive advantage through new product offerings ( $\uparrow$ Changereadiness IT capability $[9,97])$. The Outside-in IT CA allows for external integration and identification of knowledge to redirect them into the organization [52]. This includes providing information and connecting to customers and supply chain partners ( $\Theta$ Integrated IS capability [83]) or alliance partners ( $\uparrow$ IT-enabled knowledge integration capability [98]). The codification of process knowledge and the strategic use for customer purposes are also part of this CA ( $\downarrow$ Shared knowledge capability [92]). 


\section{Conclusion, Discussion and Further Research}

Due to the rapid development of digital technologies, the business environment is changing at an ever-faster pace [1]. Digitalization no longer only promotes innovations to increase operational efficiency, but changes customer needs, value creation processes, and entire markets. To respond to these changes, organizations must reconfigure and expand their resource and capability base to achieve DI [3]. However, capabilities being relevant for DI has not yet been holistically examined. The capability literature resembles a jungle of perspectives and partial considerations, which is characterized by a non-uniform world of terms and definitions. To identify relevant capabilities for DI and to name their interaction, a holistic approach is required. With the DI Capabilities Model presented, we introduce, to the best of our knowledge, the first holistic view of DI-relevant capabilities. The DI Capability Model comprises nine capability layers, 26 capability areas, and 58 capabilities that are associated with DI in high-quality scientific articles and, thus, represents a comprehensive, qualified, and structured state of the current scientific discourse. This is a valuable contribution to support further research and can be leveraged for goal-driven DI in organizations.

Our detailed analysis of different research domains on DI-relevant capabilities shows that first-order capabilities and entrepreneurial mindsets in particular are becoming increasingly important for the complex and interdisciplinary challenges of DI. It turns out that micro-foundations such as culture, work organization, and individual capabilities are important antecedents for the successful development of DI-relevant capabilities [11]. Interestingly, digital technology capabilities (e.g., artificial intelligence, machine learning, Big Data) are not very pronounced in the model presented. This may be due to the fact that relevant capabilities are more pronounced in terms of the application of and value creation by digital technologies and do not relate to individual digital technologies. It is also possible that such specific capabilities are not included in our data set due to their novelty and, thus, are not published so far.

Due to the nature of our research, this study comes up with some limitations. As we conducted a structured literature review, further research could widen the scope and more broadly define inclusion criteria to cover more literature. Thus, further research should investigate every capability layer with an in-depth analysis of literature and include, for example, conference publications to grasp latest research findings e.g., [99] who cleared up the space concerning business process management capabilities. Furthermore, our qualitative analysis of the capability definitions used as well as their consolidation and condensation into the presented DI Capability Model is not free of bias. Future research should investigate the identified layers, areas, and capabilities more thoroughly and empirically confirm their interaction. 


\section{References}

1. Nambisan, S.: Digital Entrepreneurship: Toward a Digital Technology Perspective of Entrepreneurship. Entrepreneurship Theory and Practice 41, 1029-1055 (2017)

2. Loonam, J., Eaves, S., Kumar, V., Parry, G.: Towards digital transformation: Lessons learned from traditional organizations. Strategic Change 27, 101-109 (2018)

3. Kohli, R., Melville, N.P.: Digital innovation: A review and synthesis. Info Systems J 29, 200-223 (2018)

4. Fichman, R.: Going Beyond the Dominant Paradigm for Information Technology Innovation Research: Emerging Concepts and Methods. J. Assoc. Inf. Syst. 5, 314-355 (2004)

5. Ciriello, R.F., Richter, A., Schwabe, G.: Digital Innovation. Bus. Inf. Syst. Eng. 60, $563-$ $569(2018)$

6. Vega, A., Chiasson, M.: A comprehensive framework to research digital innovation: The joint use of the systems of innovation and critical realism. The Journal of Strategic Information Systems 28, 242-256 (2019)

7. Yoo, Y., Henfridsson, O., Lyytinen, K.: Research Commentary - The New Organizing Logic of Digital Innovation: An Agenda for Information Systems Research. Information Systems Research 21, 724-735 (2010)

8. Gupta, M., George, J.F.: Toward the development of a big data analytics capability. Information \& Management 53, 1049-1064 (2016)

9. Zhou, K.Z., Wu, F.: Technological capability, strategic flexibility, and product innovation. Strat. Mgmt. J. 23, n/a-n/a (2009)

10. Eggers, J.P., Kaul, A.: Motivation and Ability? A Behavioral Perspective on the Pursuit of Radical Invention in Multi-Technology Incumbents. Acad Manage J 61, 67-93 (2018)

11. Wilden, R., Devinney, T.M., Dowling, G.R.: The Architecture of Dynamic Capability Research Identifying the Building Blocks of a Configurational Approach. Acad. Manag. ANNALS 10, 997-1076 (2016)

12. Bharadwaj, A.S.: A Resource-Based Perspective on Information Technology Capability and Firm Performance: An Empirical Investigation. MIS Quarterly 24, 169 (2000)

13. Lioukas, C.S., Reuer, J.J., Zollo, M.: Effects of Information Technology Capabilities on Strategic Alliances: Implications for the Resource-Based View. Journal of Management Studies 53, 161-183 (2016)

14. Bhatt, G.D., Grover, V.: Types of Information Technology Capabilities and Their Role in Competitive Advantage: An Empirical Study. J. Manag. Inf. Syst 22, 253-277 (2005)

15. Levallet, N., Chan, Y.E.: Role of digital capabilities in unleashing the power of managerial improvisation. MIS Quarterly Executive 17, 4-21 (2018)

16. Yoo, Y., Boland, R.J., Lyytinen, K., Majchrzak, A.: Organizing for Innovation in the Digitized World. Industrial and Corporate Change 23, 1398-1408 (2012)

17. Teece, D.J.: Dynamic Capabilities: Routines versus Entrepreneurial Action. Journal of Management Studies 49, 1395-1401 (2012)

18. Helfat, C.E., Raubitschek, R.S.: Dynamic and integrative capabilities for profiting from innovation in digital platform-based ecosystems. Research Policy 47, 1391-1399 (2018)

19. Rothaermel, F.T., Hess, A.M.: Building Dynamic Capabilities: Innovation Driven by Individual-, Firm-, \& Network-Level Effects. Industrial and Corporate Change 18, 898-921 (2007) 
20. Helfat, C.E., Peteraf, M.A.: The dynamic resource-based view: capability lifecycles. Strat. Mgmt. J. 24, 997-1010 (2003)

21. Schryen, G.: Revisiting IS business value research: what we already know, what we still need to know, and how we can get there. Eur. J. Inf. Syst 22, 139-169 (2013)

22. Nambisan, S., Lyytinen, K., Majchrzak, A., Song, M.: Digital Innovation Management: Reinventing Innovation Management Research in a Digital World. MIS Quarterly 41, $223-$ 238 (2017)

23. Zuppo, C.M.: Defining ICT in a Boundaryless World : The Development of a Working Hierarchy. IJMIT 4, 13-22 (2012)

24. Rogers, E.M.: Diffusion of innovations. Free Press, New York, NY (1983)

25. Powell, T.C.: Research notes and communications strategic planning as competitive advantage. Strat. Mgmt. J. 13, 551-558 (1992)

26. Grant, R.M.: The Resource-Based Theory of Competitive Advantage: Implications for Strategy Formulation. Calif. Manag. Rev. 33, 114-135 (1991)

27. Amit, R., Schoemaker, P.J.H.: Strategic assets and organizational rent. Strat. Mgmt. J. 14, 33-46 (1993)

28. Hafeez, K., Zhang, Y., Malak, N.: Core competence for sustainable competitive advantage: a structured methodology for identifying core competence. IEEE Trans. Eng. Manage. 49, 28-35 (2002)

29. Hine, D., Parker, R., Pregelj, L., Verreynne, M.-L.: Deconstructing and reconstructing the capability hierarchy. Industrial and Corporate Change 23, 1299-1325 (2014)

30. Paulhus, D.L., Martin, C.L.: The structure of personality capabilities. Journal of Personality and Social Psychology 52, 354-365 (1987)

31. Helfat, C.E., Peteraf, M.A.: Understanding dynamic capabilities: progress along a developmental path. Strategic Organization 7, 91-102 (2009)

32. Collis, D.J.: Research Note: How Valuable are Organizational Capabilities? Strat. Mgmt. J. 15, 143-152 (1994)

33. Winter, S.G.: Understanding dynamic capabilities. Strat. Mgmt. J. 24, 991-995 (2003)

34. Teece, D.J.: A dynamic capabilities-based entrepreneurial theory of the multinational enterprise. J Int Bus Stud 45, 8-37 (2014)

35. Zollo, M., Winter, S.G.: Deliberate Learning and the Evolution of Dynamic Capabilities. Industrial and Corporate Change 13, 339-351 (2002)

36. Gregor: The Nature of Theory in Information Systems. MIS Quarterly 30, 611 (2006)

37. Webster, J., Watson, R.T.: Analyzing the Past to Prepare for the Future: Writing a Literature Review. MIS Quarterly 26, xiii-xxiii (2002)

38. Templier, M., Paré, G.: A Framework for Guiding and Evaluating Literature Reviews. Communications of the Association for Information Systems 37 (2015)

39. Wolfswinkel, J.F., Furtmueller, E., Wilderom, C.P.M.: Using grounded theory as a method for rigorously reviewing literature. Eur. J. Inf. Syst 22, 45-55 (2013)

40. O'Reilly, C.A., Tushman, M.L.: Ambidexterity as a dynamic capability: Resolving the innovator's dilemma. Research in Organizational Behavior 28, 185-206 (2008)

41. Sharma, S., Vredenburg, H.: Proactive corporate environmental strategy and the development of competitively valuable organizational capabilities. Strat. Mgmt. J. 19, 729-753 (1998) 
42. Voss, G.B., Voss, Z.G.: Competitive Density and the Customer Acquisition-Retention Trade-Off. Journal of Marketing 72, 3-18 (2008)

43. Subramaniam, M., Youndt, M.A.: The Influence of Intellectual Capital on the Types of Innovative Capabilities. Acad Manage J 48, 450-463 (2005)

44. Krasnikov, A., Jayachandran, S.: The Relative Impact of Marketing, Research-and-Development, and Operations Capabilities on Firm Performance. Journal of Marketing 72, 1-11 (2008)

45. Rothaermel, F.T., Hill, C.W.L.: Technological Discontinuities and Complementary Assets: A Longitudinal Study of Industry and Firm Performance. Industrial and Corporate Change $16,52-70$ (2005)

46. Narasimhan, O., Rajiv, S., Dutta, S.: Absorptive Capacity in High-Technology Markets: The Competitive Advantage of the Haves. Marketing Science 25, 510-524 (2006)

47. Danneels, E.: Organizational antecedents of second-order competences. Strat. Mgmt. J. 29, 519-543 (2008)

48. Danneels, E.: Survey measures of first- and second-order competences. Strat. Mgmt. J. 37, 2174-2188 (2016)

49. Ethiraj, S.K., Kale, P., Krishnan, M.S., Singh, J.V.: Where do capabilities come from and how do they matter? A study in the software services industry. Strat. Mgmt. J. 26, 25-45 (2005)

50. Mithas, Ramasubbu, Sambamurthy: How Information Management Capability Influences Firm Performance. MIS Quarterly 35, 237 (2011)

51. Koufteros, X., Verghese, A.J., Lucianetti, L.: The effect of performance measurement systems on firm performance: A cross-sectional and a longitudinal study. Journal of Operations Management 32, 313-336 (2014)

52. Roberts, Galluch, Dinger, Grover: Absorptive Capacity and Information Systems Research: Review, Synthesis, and Directions for Future Research. MIS Quarterly 36, 625 (2012)

53. Jansen, J.J.P., van den Bosch, F.A.J., Volberda, H.W.: Managing Potential and Realized Absorptive Capacity: How do Organizational Antecedents Matter? Acad Manage J 48, 999-1015 (2005)

54. Townsend, D.M., Busenitz, L.W.: Turning water into wine? Exploring the role of dynamic capabilities in early-stage capitalization processes. J. Bus. Ventur. 30, 292-306 (2015)

55. Rai, A., Arikan, I., Pye, J., Tiwana, A.: Fit and Misfit of Plural Sourcing Strategies and ITEnabled Process Integration Capabilities: Consequences of Firm Performance in the U.S. Electric Utility Industry. MIS Quarterly 39, 865-885 (2015)

56. Eggers, J.P.: All experience is not created equal: learning, adapting, and focusing in product portfolio management. Strat. Mgmt. J. 33, 315-335 (2012)

57. Anand, G., Ward, P.T., Tatikonda, M.V., Schilling, D.A.: Dynamic capabilities through continuous improvement infrastructure. J Manage 27, 444-461 (2009)

58. Benner, M.J., Tushman, M.L.: Exploitation, Exploration, and Process Management: The Productivity Dilemma Revisited. The Academy of Management Review 28, 238 (2003)

59. Ayabakan, S., Bardhan, I.R., Zheng, Z.: A Data Envelopment Analysis Approach to Estimate IT-Enabled Production Capability. MIS Quarterly 41, 189-205 (2017) 
60. Wilden, R., Gudergan, S.P.: The impact of dynamic capabilities on operational marketing and technological capabilities: investigating the role of environmental turbulence. J. of the Acad. Mark. Sci. 43, 181-199 (2015)

61. Song, M., Di Benedetto, C.A., Nason, R.W.: Capabilities and financial performance: the moderating effect of strategic type. J. of the Acad. Mark. Sci. 35, 18-34 (2007)

62. Danneels, E.: The dynamics of product innovation and firm competences. Strat. Mgmt. J. 23, 1095-1121 (2002)

63. Moorman, C., Slotegraaf, R.J.: The Contingency Value of Complementary Capabilities in Product Development. Journal of Marketing Research 36, 239 (1999)

64. Blyler, M., Coff, R.W.: Dynamic capabilities, social capital, and rent appropriation: ties that split pies. Strat. Mgmt. J. 24, 677-686 (2003)

65. Branzei, O., Vertinsky, I.: Strategic pathways to product innovation capabilities in SMEs. J. Bus. Ventur. 21, 75-105 (2006)

66. Pil, F.K., Cohen, S.K.: Modularity: Implications for Imitation, Innovation, and Sustained Advantage. Acad. Manag. Rev 31, 995-1011 (2006)

67. Setia, P., Venkatesh, V., Joglekar, S.: Leveraging Digital Technologies: How Information Quality Leads to Localized Capabilities and Customer Service Performance. MIS Quarterly 37, 565-590 (2013)

68. Weerawardena, J., Mort, G.S., Salunke, S., Knight, G., Liesch, P.W.: The role of the market sub-system and the socio-technical sub-system in innovation and firm performance: a dynamic capabilities approach. J. of the Acad. Mark. Sci. 43, 221-239 (2015)

69. Kor, Y.Y., Mahoney, J.T.: How dynamics, management, and governance of resource deployments influence firm-level performance. Strat. Mgmt. J. 26, 489-496 (2005)

70. Ramani, G., Kumar, V.: Interaction Orientation and Firm Performance. Journal of Marketing 72, 27-45 (2008)

71. Zott, C.: Dynamic capabilities and the emergence of intraindustry differential firm performance: insights from a simulation study. Strat. Mgmt. J. 24, 97-125 (2003)

72. Nenonen, S., Storbacka, K., Windahl, C.: Capabilities for market-shaping: triggering and facilitating increased value creation. J. of the Acad. Mark. Sci. 47, 617-639 (2019)

73. Makadok, R.: Toward a synthesis of the resource-based and dynamic-capability views of rent creation. Strat. Mgmt. J. 22, 387-401 (2001)

74. Franco, A.M., Sarkar, M.B., Agarwal, R., Echambadi, R.: Swift and Smart: The Moderating Effects of Technological Capabilities on the Market Pioneering-Firm Survival Relationship. Management Science 55, 1842-1860 (2009)

75. Walter, A., Auer, M., Ritter, T.: The impact of network capabilities \& entrepreneurial orientation on university spin-off performance. J. Bus. Ventur. 21, 541-567 (2006)

76. Leiblein, M.J., Madsen, T.L.: Unbundling competitive heterogeneity: incentive structures and capability influences on technological innovation. Strat. Mgmt. J. 30, 711-735 (2009)

77. Jiang, R.J., Tao, Q.T., Santoro, M.D.: Alliance portfolio diversity and firm performance. Strat. Mgmt. J. 31, 1136-1144 (2010)

78. Giudici, A., Reinmoeller, P., Ravasi, D.: Open-System Orchestration as a Relational Source of Sensing Capabilities: Evidence from a Venture Association. Acad Manage J 61, 1369-1402 (2018)

79. Lorenzoni, G., Lipparini, A.: The leveraging of interfirm relationships as a distinctive organizational capability: a longitudinal study. Strat. Mgmt. J. 20, 317-338 (1999) 
80. Leiblein, M.J.: What Do Resource- and Capability-Based Theories Propose? J Manage 37, 909-932 (2011)

81. Volberda, H.W., Foss, N.J., Lyles, M.A.: PERSPECTIVE-Absorbing the Concept of Absorptive Capacity: How to Realize Its Potential in the Organization Field. Industrial and Corporate Change 21, 931-951 (2010)

82. Phene, A., Almeida, P.: Innovation in multinational subsidiaries: The role of knowledge assimilation and subsidiary capabilities. J Int Bus Stud 39, 901-919 (2008)

83. Setia, P., Patel, P.C.: How information systems help create OM capabilities: Consequents and antecedents of operational absorptive capacity. Journal of Operations Management 31, 409-431 (2013)

84. Vera, D., Nemanich, L., Vélez-Castrillón, S., Werner, S.: Knowledge-Based and Contextual Factors Associated with R\&D Teams' Improvisation Capability. J Manage 42, 1874 1903 (2016)

85. Lewin, A.Y., Massini, S., Peeters, C.: Microfoundations of Internal and External Absorptive Capacity Routines. Industrial and Corporate Change 22, 81-98 (2011)

86. Suddaby, R., Coraiola, D., Harvey, C., Foster, W.: History and the micro-foundations of dynamic capabilities. Strat. Mgmt. J. 41, 530-556 (2020)

87. Chae, H.-C., Koh, C.E., Prybutok, V.R.: Information Technology Capability and Firm Performance: Contradictory Findings \& Their Possible Causes. MIS Quarterly 38, 305-326 (2014)

88. Drnevich, P.L., Croson, D.C.: Information Technology and Business-Level Strategy: Toward an Integrated Theoretical Perspective. MIS Quarterly 37, 483-509 (2013)

89. Mishra, S., Modi, S.B., Animesh, A.: The relationship between information technology capability, inventory efficiency, and shareholder wealth: A firm-level empirical analysis. Journal of Operations Management 31, 298-312 (2013)

90. Aral, S., Weill, P.: IT Assets, Organizational Capabilities, and Firm Performance: How Resource Allocations and Organizational Differences Explain Performance Variation. Industrial and Corporate Change 18, 763-780 (2007)

91. Lu, Ramamurthy, K.: Understanding the Link Between Information Technology Capability and Organizational Agility: An Empirical Examination. MIS Quarterly 35, 931 (2011)

92. Ray, Muhanna, Barney: Information Technology and the Performance of the Customer Service Process: A Resource-Based Analysis. MIS Quarterly 29, 625 (2005)

93. Weigelt, C.: Leveraging supplier capabilities: The role of locus of capability deployment. Strat. Mgmt. J. 34, 1-21 (2013)

94. Wang, T., Chen, Y.: Capability Stretching in Product Innovation. J Manage 44, 784-810 (2018)

95. Wu, L., Lou, B., Hitt, L.: Data Analytics Supports Decentralized Innovation. Management Science 65, 4863-4877 (2019)

96. Eggers, J.P., Park, K.F.: Incumbent Adaptation to Technological Change: The Past, Present, and Future of Research on Heterogeneous Incumbent Response. Acad. Manag. ANNALS 12, 357-389 (2018)

97. Clark, C.E., Cavanaugh, N.C., Brown, C.V., Sambamurthy, V.: Building Change-Readiness Capabilities in the IS Organization: Insights from the Bell Atlantic Experience. MIS Quarterly 21, 425 (1997) 
98. Liu, Y., Ravichandran, T.: Alliance Experience, IT-Enabled Knowledge Integration, and Ex Ante Value Gains. Industrial and Corporate Change 26, 511-530 (2015)

99. Kerpedzhiev, G.D., König, U.M., Röglinger, M., Rosemann, M.: An Exploration into Future Business Process Management Capabilities in View of Digitalization. Bus. Inf. Syst. Eng. 14, 33 (2020) 